\title{
A relação entre eudaimonia e dor: uma aproximação entre Aristóteles e Schopenhauer
}

\section{The relation between eudaimonia and pain: an approach between Aristotle and Schopenhauer}

JOSIELI APARECIDA OPALCHUKA ${ }^{26}$

RESUMO: Ao desenvolver o conceito de eudaimonia, Aristóteles coloca as virtudes enquanto meios para alcançá-la. Antagonicamente às virtudes estão os vícios, tanto os do excesso, quanto os da falta corrompem e afastam o homem do caminho do Sumo Bem, o levando à dor, caracterizando-se, portanto, como um sentimento negativo. Já o filósofo Arthur Schopenhauer, coloca a dor como única coisa positiva que se faz presente na vida humana, já que é intrínseca: o homem é dotado de vontade, sempre querendo algo, sendo essa vontade que causa a dor. Assim, a felicidade é um sentimento que aparece quando a dor é interrompida.

Palavras-chave: Eudaimonia. Dor. Virtudes.

ABSTRACT: To elucidate his concept of eudaimonia, Aristotle organizes the virtues in ways to reaches it. Oppositely to the virtues are the addictions, both, in the excess or in lack, corrupts and back away the mankind of the Greatest Good, bringing pain and characterizing to a bad feeling. Otherwise, Arthur Schopenhauer, elucidates pain as the one thing positive that does presence in the human life, since its intrinsic: the mankind is endowed with willpower, always wanting something, and this willpower is the main cause of pain. In this manner, happiness is a feeling that shows when pain is interrupted.

Keywords: Eudaimonia. Pain. Virtues.

${ }^{26}$ Acadêmica de filosofia da Universidade Estadual do Oeste do Paraná. Bolsista do Programa de Educação Tutorial - Filosofia (PET). Endereço eletrônico: josi.aop@gmail.com . 
A relação entre eudaimonia e dor: uma aproximação entre Aristóteles e Schopenhauer

O filósofo da antiguidade, Aristóteles, na sua obra intitulada "Ética a Nicômaco", desenvolve o conceito da felicidade (eudaimonia), ou sumo bem. Em tese, a felicidade só é possível para o homem virtuoso, ou seja, aquele que sabe deliberar as possíveis naturezas do bem, sendo a da sabedoria ou da contemplação a atividade mais perfeita do homem, visto que a razão é própria da humanidade. Deste modo, a eudaimonia não deve ser associada aos prazeres do corpo, nem às honrarias ou riquezas, pois que geralmente levam às vicissitudes.

Assim, a eudaimonia é uma atividade da alma, onde a razão e a virtude melhor e mais completa agem em conformidade. Visto que o homem feliz deve necessariamente agir, e agir bem, a eudaimonia consiste num modo de agir virtuoso, prudente, bom; e como dela também faz parte a razão, que deve influenciar na vontade e controlar as paixões e impulsos, a eudaimonia também consiste num modo de viver contemplativo, onde se delibera bem, para agir bem. Dos demais bens, alguns devem estar como condições prévias da felicidade, e outros são naturalmente cooperantes e úteis como instrumentos, como a liberdade e o ócio. Além disso, como deve consistir em agir bem e viver bem, a vida do cidadão da polis é o melhor dos fins, pois na política o homem dedica o melhor dos seus esforços para com que os cidadãos sejam bons e capazes de nobres ações. Assim sendo, o político deve ocupar-se em estudar a alma considerando as virtudes e o bem viver e o bem agir. Aristóteles ainda afirma que o homem virtuoso é aquele que age tendo em vista a moderação e a prudência, evitando os prazeres, e, portanto, buscando aquilo que é isento de dor.

Reteremos-nos aqui, à análise do livro VI, VII e X, especialmente, onde o autor explicita os principais conceitos fundamentais na 
construção argumentativa da eudaimonia e dando margem a discussão proposta sobre a dor.

A felicidade compreende uma vida completa, de acordo com sua função e virtude, assim, nenhum homem feliz pode tornar-se desgraçado porquanto jamais praticará atos odiosos e vis, deixando evidente que a eudaimonia não se trata de momentos superficiais, breves e levianos, mas de uma vida guiada pelo bem. Ainda, existem na alma, distintas por definição, mas inseparáveis por natureza, uma parte repleta de razão e outra que dela carece (vegetativa e desderativa). Já a parte dotada de razão, portanto ativa, evidenciará a Arete dianoética, ou seja, intelectual, o pleno uso razão, que resultará num modo de viver e agir virtuosos. Assim como acontece com a alma e a razão que é parte constituinte da eudaimonia, o mesmo ocorre com as virtudes, que realizam o aperfeiçoamento do indivíduo.

A partir disso, Aristóteles define a virtude em intelectual e moral. As virtudes intelectuais, as dianoéticas, necessitam de aprendizagem, exigindo assim, tempo e experiência. Já as virtudes morais (éticas) resultam do hábito, ou seja, da repetição constante de determinado ato, num determinado sentido. Infere-se, então, que o julgamento do homem em ser bom ou ser mau, vem de como ele reage em determinadas circunstâncias, visto que, o homem, segundo Aristóteles, não nasce bom nem mau. A virtude se dá no exercício das atividades, por exemplo, só seremos bravos, cometendo atos de bravura, ou como o autor cita só se é justo praticando atos justos. Assim, o homem que só age bem será bom, o que toma más atitudes será mau. Deste modo, se define o caráter dos homens: se em presença de perigo e pelo hábito do medo, ou da ousadia, se torna valente ou covarde. Ou seja, as diferenças de caráter nascem de atividades 
A relação entre eudaimonia e dor: uma aproximação entre Aristóteles e Schopenhauer

semelhantes. Por isso se deve deliberar sobre cada ato.

O agir de modo contrário à virtude, praticando o mal, é chamado de vício, kakai. A virtude se encontra na alma e nela são observadas três manifestações: 1) as faculdades, que é o que dita se somos capazes ou não de sentir as paixões, em contrapartida, quando nos sentimos chateados ou alegres não deliberamos ou escolhemos sobre isso, apenas sentimos e as virtudes são modalidades de escolhas, ou envolvem escolhas. Logo não pode ser a essa que pertence às virtudes, 2) as paixões ou emoções, por exemplo, medo, alegria, desejo, em geral os sentimentos que são acompanhados de prazer ou dor e 3) as disposições de caráter, que devem ser da espécie que o torna bom e que o faz desempenhar bem a sua função, ou seja, é o bom hábito, que não é paixão nem faculdade. Além disso, não pode ser deficiente, ou seja, padecer de carência ou excesso, mas deve ser excelente, ou seja, ser o meio termo (mesótis) entre o excesso e a falta. A virtude moral é precisamente, a justa medida entre os dois vícios, o de excesso e o de carência. Esse ponto mediano é muito difícil de ser encontrado, por isso ser bom, ou virtuoso, não é uma simples tarefa, pois consiste em encontrar o ponto entre dois extremos.

A escolha é fundamental na formação do caráter moral e envolve o pensamento, pressupondo uma razão ativa. Além disso, um homem virtuoso que age bem e vive bem, deve atuar sempre tendo em vista, a conformidade entre a razão e a virtude que o aproxima da eudaimonia, o sumo bem, que é a finalidade do homem.

Focaremos agora no que tange ao homem que age com vistas à moderação evitando os prazeres, e à prudência e, portanto, busca aquilo que é isento de dor. Para Aristóteles, a dor advém dos sentimentos que envolvem o prazer (em sua ausência) e, por 
consequência a acentuação da dor (na ausência dos prazeres). Falamos aqui prazeres do corpo, ou as formas excessivas desses, que resultam em um desregramento dos sentidos. É por conta disso, que o homem moderado evita os prazeres em excesso, porém não deixa de experimentar os prazeres. Portanto, o homem virtuoso busca não os prazeres, e sim a ausência da dor.

Atento a isto, o filósofo alemão do século XIX, Arthur Schopenhauer, afirma que o eudaimonismo estaria situado entre o estoicismo, que impõe a privação dos prazeres, desconsiderando o homem como ser repleto de vontade, e o maquiavelismo, em que a busca pela felicidade depende do outro, pressupondo, neste, a razão necessária para tal. $\mathrm{O}$ eudaimonismo aristotélico nos ensina como viver da maneira mais feliz possível, tendo alguns prazeres enquanto resultados de boas ações, e sem utilizar outros objetos ou pessoas como possíveis meios para alcançar a felicidade.

Schopenhauer frisa que a felicidade completa e positiva é impossível, podendo atingir, no máximo, momentos relativamente menos dolorosos. Deste modo, o que podemos é fazer é transpor aquilo que depende estritamente de nós. Portanto, o eudaimonismo deveria se subdividir em duas máximas em relação ao nosso comportamento com nós mesmos e com os outros. $\mathrm{O}$ autor pretende atingir com isto, serenidade de espírito, que segundo ele, determina a capacidade de sentir tristeza ou alegria, saúde do corpo, paz de espírito (intimamente ligada à prudência) e os bens exteriores.

Faz-se necessário, também, falar sobre o caráter humano, com maior ênfase no caráter adquirido, aquele que se obtém individualmente, com a prática da vida no mundo e aquele que julgamos bom ou mau em determinado indivíduo. Há também o 
A relação entre eudaimonia e dor: uma aproximação entre Aristóteles e Schopenhauer

caráter empírico e o caráter inteligível, o último é o modo de manifestação do primeiro. O caráter inteligível é imutável, já que é fenômeno natural, e se fosse apenas por esse viés o homem iria mostrar-se sempre da mesma forma, já que de fato não depende dele o caráter que mostra. Porém o que se dá é que o caráter empírico, como impulso natural, é de fato, irracional, mas suas manifestações são "perturbadas" pela razão, aumentando proporcionalmente ao à seriedade da reflexão e força de pensamento.

Como o homem encontra dentro de si as inclinações tanto para as aspirações quanto para as forças humanas, que se diferenciam de um ser para outro, dando origem à individualidade, fazendo-se clarificar por meio da experiência. Se o homem, posterior a isso, se entregar as suas inclinações iniciais, verá que em determinados estados de espírito terá inclinações totalmente divergentes em relação às primeiras. Se não soubermos lidar com o fato de ter que renunciar a certas disposições, perderemos a tranquilidade lidando com as consequências desses impulsos que não correspondem de fato com o nosso caráter. Deste modo, o simples querer algo não deve ser tomado como suficientes em si. Portanto, "o homem deve saber o que quer e saber o que pode: somente assim mostrará caráter e somente então poderá cumprir algo de bom” (SCHOPENHAUER, 2005, p.12).

Assim sendo, somente através da experiência podemos aprender o que queremos e podemos, antes disso, não dispomos de caráter e devemos levar duros golpes externos na vida, mas se aprendermos, aí adentraremos ao mundo do caráter adquirido, que, em síntese, é o conhecimento de nossa própria individualidade, das qualidades imutáveis do nosso caráter empírico, bem como a medida de nossas forças, possibilitando, assim, o desenvolvimento de nossa reflexão e 
método, não nos deixando levar por pressões externas ou um determinado estado de espírito. Deste modo, o caráter de Schopenhauer se assemelha, em certo sentido das virtudes de Aristóteles, visto que a partir do conhecimento delas, há uma otimização do agir humano.

Se conhecermos com clareza a nós mesmos e o alcance de nossas apetições, evitaremos, de modo muito seguro, a mais amarga das dores, que é o descontentamento, ou o desprazer em relação a nós mesmos que é consequência da falta de conhecimento da própria individualidade, da falsa presunção e da temeridade. Esse autoconhecimento pode ser considerado, em certa medida, como uma prudência em relação à dor.

Para ele a felicidade também se manifesta como ausência da dor. Para fazer esta aproximação, é necessário, esclarecemos o conceito de dor para Schopenhauer que se mostra intrínseca a vida. Como constantemente desejamos algo, estamos submersos na possibilidade da dor.

Para Schopenhauer, estamos continuamente desatentos e inconscientes e só saímos desse estado quando algo se choca, contraria, com nossa vontade. Nesse aspecto, vivemos em incessante dor, que o autor coloca como único sentimento positivo, e quando nos deparamos com a felicidade ou algum prazer, que são negativos, é que formamos uma dimensão do que vivemos, portanto, é a ausência de dor que nos possibilita a medição da felicidade ou intensidade de um prazer.

Desde a infância, somos condicionados a aceitar quimeras, os prazeres positivos que nos persuadem a acreditar na ilusão de uma vida menos dolorosa, ao invés de aceitar a dor, que positiva, é muito 
A relação entre eudaimonia e dor: uma aproximação entre Aristóteles e Schopenhauer

mais real, não pensaríamos em evitá-la, mas sim, evitar os prazeres, como os cínicos se propuseram como forma de escapar da eminente dor. Além disso, Schopenhauer também frisa a importância de condicionarmos nossa imaginação à mais profunda realidade, visto que ao imaginar possíveis acasos felizes e suas consequências, tornamos a realidade ainda mais indigesta e dolorosa. Ainda afirma, que para chegar a eudaimonia, é necessário viver da maneira menos infeliz possível e, neste aspecto, da maneira suportável.

Aristóteles ao falar da escolha, desejo e opinião, afirma que se prazer e dor não devem ser critérios de deliberação, visto que o indivíduo que escolhe pode atualizar o vício por intermédio da escolha ou rejeição apenas em função do prazer ou da dor que a coisa pode oferecer.

Já para Schopenhauer, não há uma questão de escolha, a dor não é um vício e sim uma realidade, e essa busca pela eudaimonia, a felicidade para qual a existência humana deve tender, não passa de uma ilusão de interrupção, ou redução elevada, do sofrimento humano.

\section{Referências bibliográficas}

ARISTÓTELES. Ética a Nicômaco. Trad. E. Bini. 2ª ed. São Paulo: Edipro, 2007.

AUBENQUE, Pierre. A prudência em Aristóteles. 2aㅡ. ed. São Paulo: Paulus, 2008.

SCHOPENHAUER, Arthur. A arte de ser feliz: exposta em 50 máximas. $2^{\underline{a}}$ ed. São Paulo: Martins Fontes, 2005.

SPINELLI, Priscilla T. A prudência na Ética Nicomaquéia de Aristóteles. São Leopoldo, RS: Unisinos, 2007. 